Informes de la Construcción Vol. 61, 516, 37-52, octubre-diciembre 2009 ISSN: 0020-0883 eISSN: 1988-3234 doi: 10.3989/ic.09.027

\title{
Diseño y construcción de muros en el primer gótico cordobés
}

\author{
Walls design and construction during the first gothic \\ of Córdoba
}

\author{
A. I. García Ortega ${ }^{(*)}$
}

\section{RESUMEN}

Las primeras iglesias cristianas de Córdoba constituyen un homogéneo conjunto, comenzado además en un corto período de tiempo a finales del siglo XIII. Esto ofrece una plataforma idónea para estudiar sus soluciones constructivas tipo, entre las que son trascendentales los sistemas de muros. Utilizando magnífica sillería, se construyen sabiendo adaptar las técnicas cristianas nortepeninsulares a las tradiciones locales y al aprovechamiento de los sillares de acarreo islámicos. Esto incidiría en el aparejo a soga y tizón mayoritariamente utilizado, aunque el muro sigue siendo el gótico de tres hojas, con dos paramentos y relleno interior. Estas características, así como la solución de cimentación, el mortero utilizado o el posible uso de la vara burgalesa como unidad de medida, suponen una manera de proceder nueva en la ciudad, apuntando a la más que probable intervención de canteros castellanos.

El análisis dimensional del conjunto permite también detectar la lógica y coherencia en la asignación de espesores a los muros. Existe gradación de los mismos según sus circunstancias y posición en el organismo arquitectónico, e igualmente coincidencias dimensionales entre los distintos edificios para un mismo tipo de muro; todo esto apunta al uso de reglas preestablecidas, posiblemente muy sencillas. Por último, el conocimiento y objetivación de todos estos aspectos aporta interesantes datos sobre el proceso edificatorio, que, frecuentemente, priorizaría las cabeceras; y también, en edificios casi destruidos como la iglesia de S. Andrés, incluso es posible elaborar hipótesis fundadas para su reconstrucción.

$173-1$

Palabras clave: muro, obra de sillería, dimensionamiento, arquitectura medieval cordobesa, gótico.

\section{SUMMARY}

The first Christian Churches of Córdoba constitute a homogeneous set, which was started up during a short period of time at the end of the XIIIth century. These facts make them an ideal set of buildings to study their typical constructive solutions, among which the wall systems are of outstanding importance. Using grand stonework, they are built adapting the Christian techniques from the North of the Iberian Peninsula to the local traditions and they make use of the available Islamic stones. This fact influenced the stonework, by the alternate positioning of the stones, one longitudinally and the next transversally. Nevertheless, the wall was gothic of three parts, with two stone walls, and an inner filling. This constructive system, together with the foundation characteristics, the mortar used, or the possible use of the measuring stick of Burgos as the measure unit, are the reflection of a new way of building in the city, and show evidence of the possible intervention of castillian stonemasons.

The dimensional analysis of the architectural set allows the detection of the underlying logic and coherence in the assignment of the wall widths. There is graduation among them according to their circumstances and their positions within the building, as well as dimensional coincidences among the different buildings for the same type of wall. All of these show evidence of preestablished rules, probably very easy. Finally, the objective knowledge of all these aspects contribute interesting data about the building process, that frequently prioritizes the apses; and also, in almost destroyed buildings like the $S$. Andrés Church, it is possible to elaborate rigorous hypothesis for its reconstruction.

Keywords: wall, stonework, dimensioning, medieval architecture of Córdoba, gothic. 
1. Derrumbe de arcada norte de Santiago (año 1988). Detalles de entronque con cabecera y hastial.

\section{EL PLANTEAMIENTO DE LA CUESTIÓN}

En Córdoba, la antigua capital del califato, durante el último tercio del s. XIII se inician las primeras construcciones cristianas de cierta importancia, principalmente iglesias, impulsadas por el nuevo poder castellano que conquista la ciudad en 1236. Unos edificios que en su mayoría, aun sin desprenderse de las persistentes formas cistercienses, incorporan algunas novedades del gótico burgalés. También, para levantar con agilidad y economía los nuevos contenedores religiosos, se opta por un sencillo tipo basilical, un modelo repetido insistentemente que nos ha dejado un amplio y homogéneo conjunto arquitectónico, además prácticamente coetáneo. Por todo ello, estas iglesias constituyen una plataforma idónea, e infrecuente, para estudiar cómo se resuelven, al margen de particularismos, los aspectos constructivos en el arranque del gótico andaluz.

Junto a formas y tipología, con fuerte impronta castellana, se importan modos de hacer, técnicas constructivas, etc., que en conjunción con las tradiciones locales y los inevitables condicionantes del material, implementarán soluciones constructivas adaptadas a las particulares circunstancias del momento. Los muros, constituidos por dos hojas de sillería y relleno interior, fueron uno de los sistemas constructivos más importantes del nuevo edificio; tipológicamente conformaban su planta y en la erección de éste suponían una de las partidas de obra de mayor repercusión económica y necesidades de material. Pese a todo esto, su completa definición constructiva carece todavía de un estudio arquitectónico específico, pasando inadvertida en los diferentes trabajos que hasta la fecha han abordado, desde múltiples puntos de vista, las primeras iglesias de la ciudad de Córdoba. Esta tarea, además, va a aportar interesantes indicios sobre el proceder del constructor gótico en cuestiones como el dimensionamiento estructural, la adaptación de las técnicas al uso, la influencia del material, el proceso constructivo del edificio, o incluso quiénes pudieron ser sus ejecutores materiales. Se trata, una vez más, de aspectos ignorados o que, pese a su evidente interrelación, rara vez son abordados conjuntamente en los estudios existentes; muchos de ellos, además, se limitan a un único edificio.

Junto al análisis directo del conjunto de las fábricas, tanto constructivo como dimensional, para este trabajo se han rastreado los datos conocidos por las intervenciones practicadas en las iglesias, muchos de ellos recogidos en documentos o expedientes oficiales inéditos (1), o fruto del seguimiento del autor a los edificios durante más de una década. Afortunadamente, desde el último cuarto del s. XX, han sido frecuentes las restauraciones, consolidaciones y refuerzos, inspecciones tras derrumbes, estudios $\mathrm{O}$ catas específicas, prospecciones arqueológicas, etc.; esto ha permitido conocer multitud de pormenores constructivos, a veces visibles por un limitado período (figura 1). Un conocimiento fragmentario, si se considera por edificios aislados, pero mucho más significativo al tener en cuenta su carácter de grupo, capaz de constituir una base de datos suficiente para abordar el trabajo que aquí se plantea.

\section{LAS PRIMERAS IGLESIAS DE CÓRDOBA Y SUS ARTÍFICES}

La construcción civil o militar de los primeros tiempos tras la conquista del valle
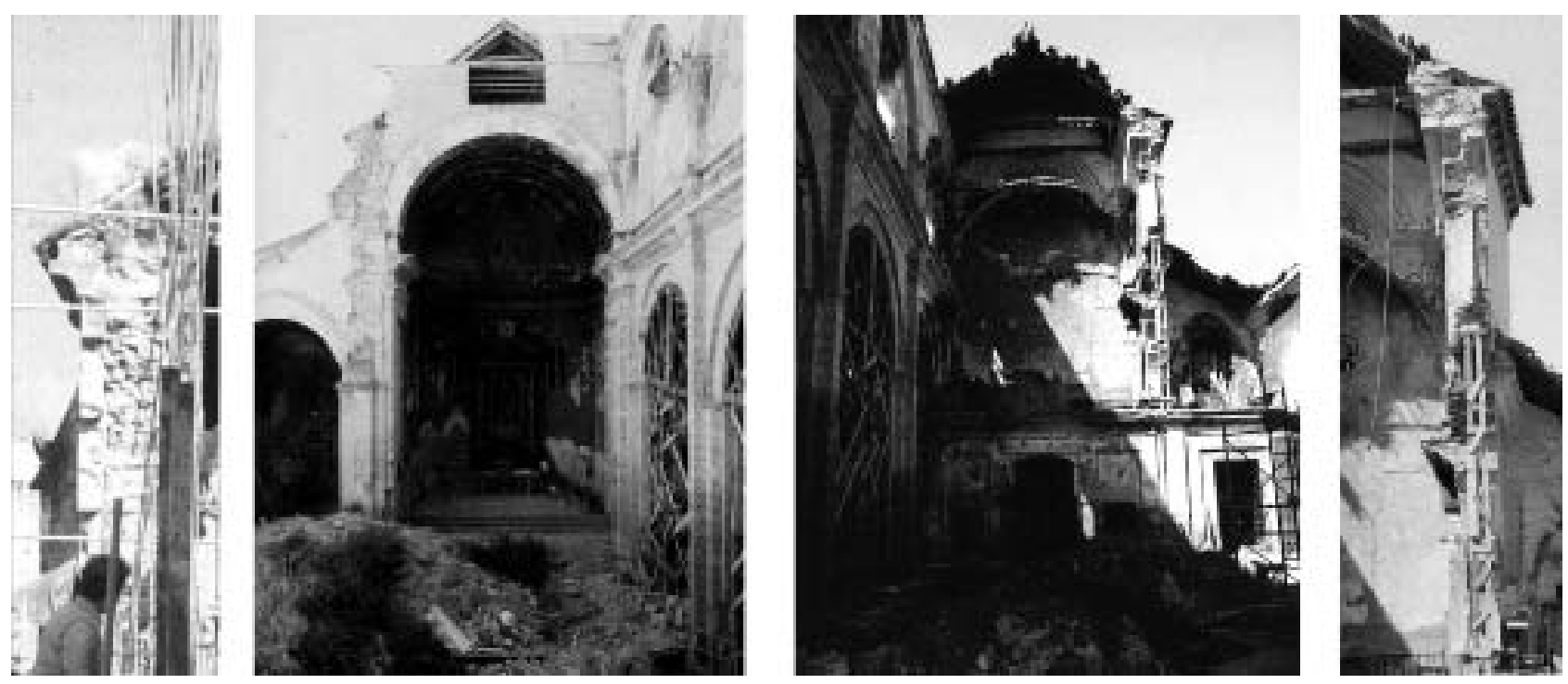


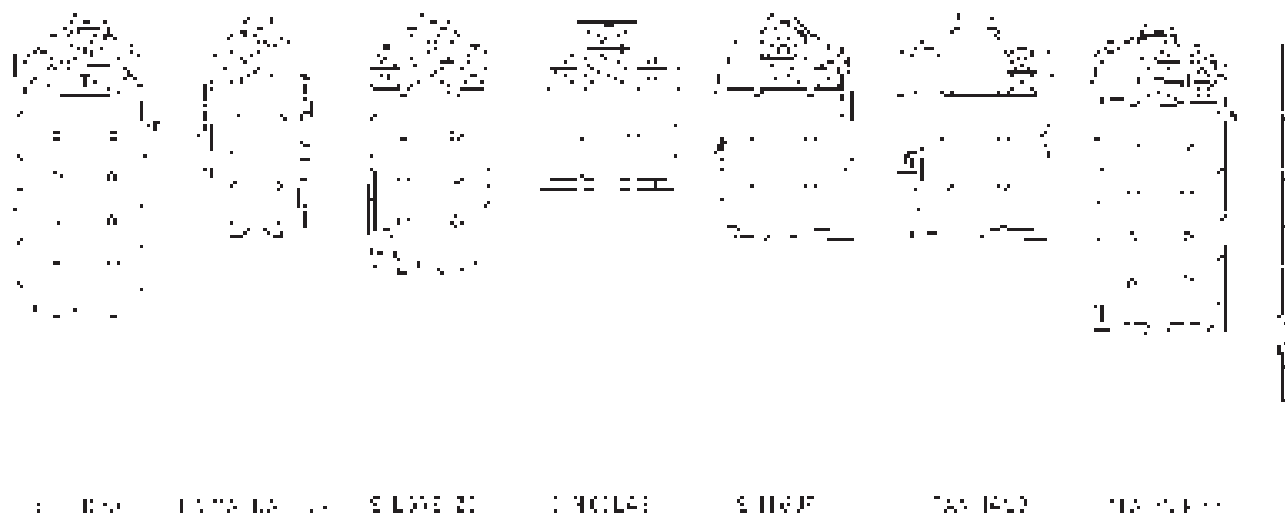

del Guadalquivir fue muy escasa, y en Córdoba tan sólo se destaca la obra del nuevo Alcázar cristiano, ya en el siglo XIV. En el ámbito religioso, y a la espera todavía de las primeras catedrales andaluzas, será en los modestos templos parroquiales de Córdoba, Jerez, y aisladamente en la sevillana iglesia de Santa Ana, donde primero se aprecian las formas góticas en los nuevos territorios andalusíes; formarán parte de masivos edificios que, pese a todo, intentaran adelgazar el muro espeso del románico y tímidamente estilizar sus espacios. La pérdida o grave transformación de las parroquias jerezanas, las particularidades y arcaísmo de otros conjuntos como el jienense, o lo tardío y casi mudéjar del sevillano, deja a la producción cordobesa como una de las más nutridas y significativas del primer gótico andaluz.

Pese a que la ciudad se conquista en 1236, hasta el último tercio del doscientos no tomó forma un ambicioso programa constructivo que renovaría las viejas sedes parroquiales, alojadas en modestas y oscuras mezquitas. La pequeña iglesia de La Magdalena se tiene por la primera, a la que no en mucho tiempo debieron seguir S. Miguel, S. Lorenzo, S. Pedro, Santiago, Sta. Marina, S. Andrés (hoy casi destruido) y S. Nicolás, ésta tardíamente. El resto de las sedes parroquiales no nos han llegado, se empiezan tardíamente o la reutilización del primitivo contenedor islámico se dilató más allá de la etapa bajomedieval.

Se incluyen en este estudio el templo dominico de S. Pablo, un tanto arcaizante y coetáneo a La Magdalena, y el franciscano de S. Pedro el Real, de principios del s. XIV; en ellos junto a la coincidencia temporal concurren también claras afinidades arquitectónicas. Estos dos templos conventuales y las ocho parroquias relacionadas, constituyen el arranque de la arquitectura gótica en la ciudad, anticipándose a las capillas funerarias o a las importantes intervencio- nes en la sede catedralicia. Posteriormente, sobre la mitad del s. XIV, estarían en marcha las importantes fábricas de la colegiata de S. Hipólito y el templo conventual de S. Agustín; éstas participarían de las mismas características constructivas, demostrando la persistencia y validez de las primeras formas y técnicas implementadas en la nueva arquitectura cordobesa.

La empresa edificatoria, en su conjunto, debió desbordar las posibilidades de sus promotores en aquellos difíciles tiempos, sacudidos por las razzias islámicas, guerras civiles o frecuentes pestes y carestías. Tanto la tipología a adoptar, como las técnicas constructivas debían ser sencillas y económicas, esto permitiría dar viabilidad y acortar los plazos de obra. El modelo arquitectónico fue muy similar para la mayoría de los nuevas iglesias parroquiales y el templo dominico de S. Pablo, diferenciándose tan sólo el franciscano (figura 2). Salvo en este caso, se adopta una organización basilical de tres naves, con arcadas pétreas formalizadas con el desfasado muro armado del románico, y que sostienen techumbres de madera (figura 3). Éstas, más económicas y rápidas de ejecución que las bóvedas, serán de par y nudillo en la nave

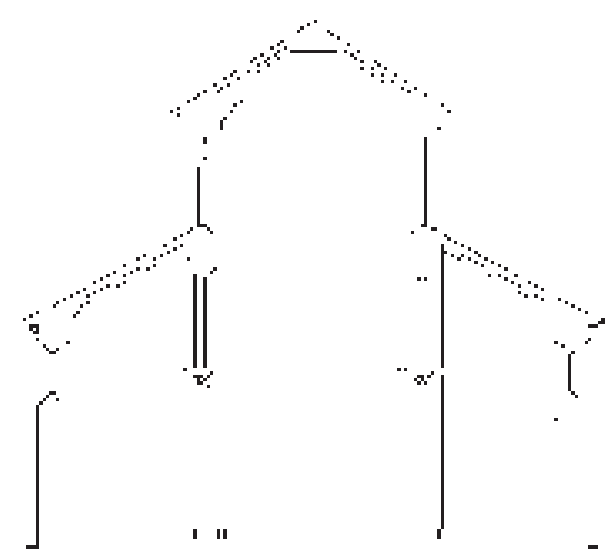

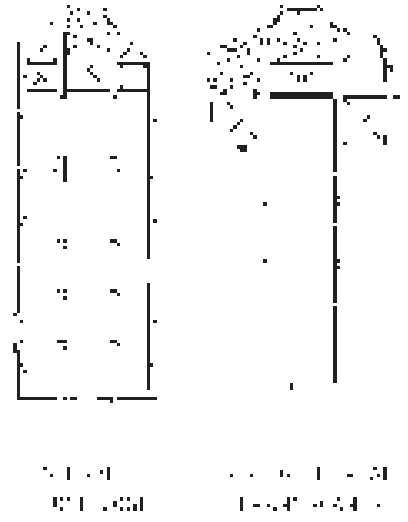

2. Plantas a la misma escala de las primeras iglesias parroquiales $y$ conventuales de Córdoba (restitución omitiendo añadidos).

3. Sección transversal "tipo" de iglesia gótica cordobesa. 
4. Fachada de S. Lorenzo.

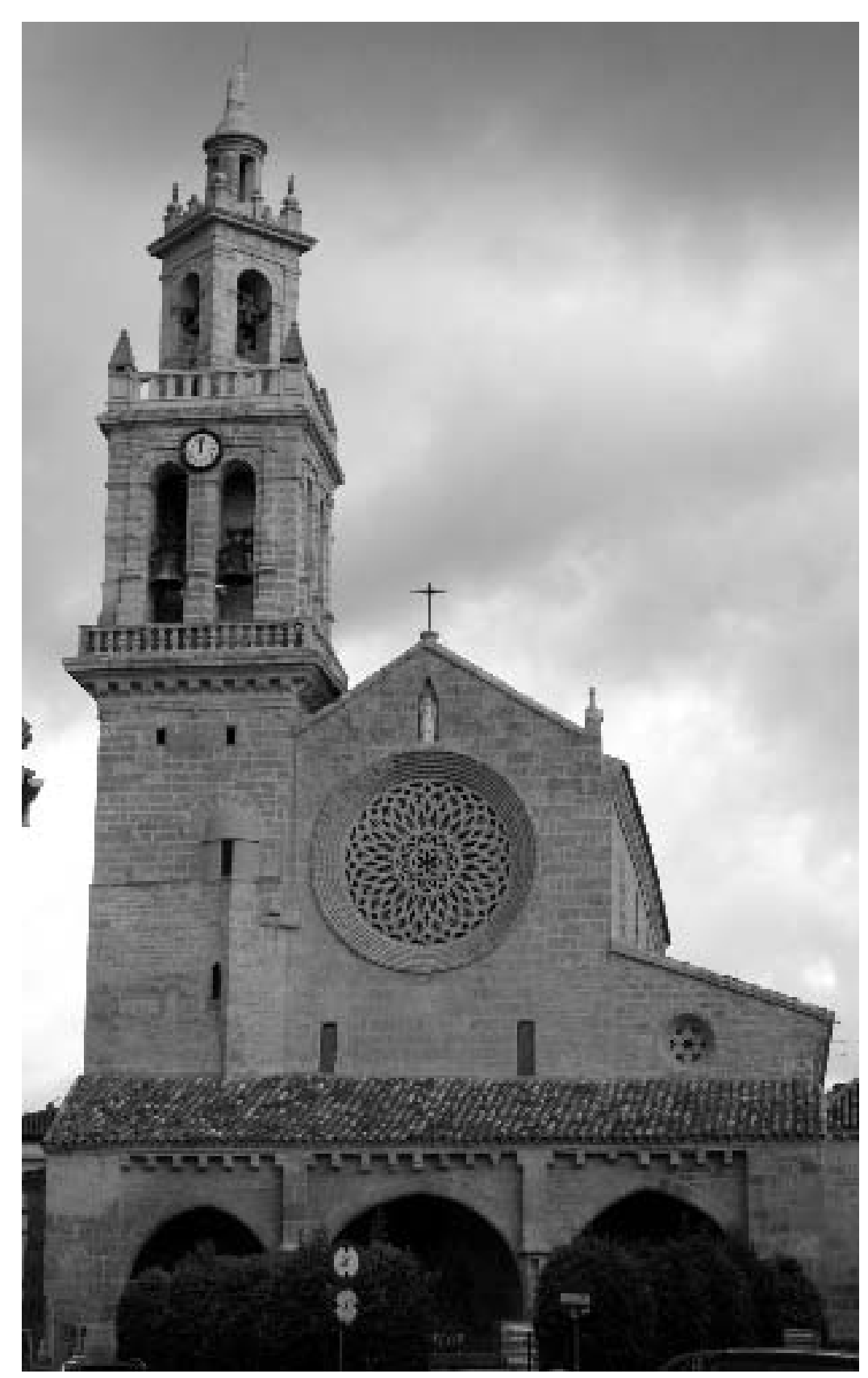

central y de colgadizo en las laterales (2). Los accesos serán por los dos costados y el hastial de los pies, un muro piñón cuyos tres niveles reproducen los de las naves y cualificado por un rosetón (figura 4).

La cabecera sería triabsidiada, con huecos estrechos y verticales, casi saeteras en algunos casos. Las capillas, rectangulares o con fondo poligonal, son bastante profundas ya que principalmente las últimas suman al tramo semioctogonal otro recto, con abovedamiento cuatripartito. Sus bóvedas responden a una formalización característica, secundada también por multitud de edificios sevillanos bajomedievales (3). Son ya ojivales, y a veces están recorridas por el característico nervio de espinazo burgalés. La solución original de la cubierta de muchos de estos ábsides sería en azotea, a jugar por las gárgolas aún hoy existentes en las iglesias de S. Miguel, S. Pedro y S. Lorenzo, aunque salvo en ésta y en el ábside norte del templo franciscano de S. Pedro el Real se han sustituido por paños inclinados de teja (figura 5).

Historiográficamente no tenemos dato alguno de autorías, pero por sus características arquitectónicas deben atribuirse a maestros de segunda fila. Superadas ya antiguas hipótesis sobre la participación del cantero real, o de maestros itinerantes que luego hubieran a marchado a Jerez y Sevilla (4), hoy tan sólo se admite genéricamente la intervención de artífices cristianos, quizás canteros burgaleses formados en los talleres del monasterio cisterciense de Las Huelgas o en la fábrica de la catedral. Será una cuestión sobre la que el estudio realizado va a aportar algún indicio nuevo.

La resolución de la cabecera, con capillas absidiales contiguas, o la formalización de algunos elementos y motivos decorativos, junto con un indudable aire cisterciense, apuntan al vínculo con el citado complejo monacal; también el característico nervio de espinazo de las bóvedas ojivales de la catedral o algún otro goticismo, constituyen préstamos casi expresos de esta fábrica burgalesa. Unas formas que tuvieron también marcada influencia en infinidad de edificios peninsulares del doscientos y aún del trescientos, evidenciando la diáspora de los artesanos formados en sus talleres. Además, el trasvase norte-sur de recursos humanos se vio fomentado por el hecho de que, según $R$. Cómez (5), los salarios de la construcción en Andalucía y Extremadura eran más altos que los del área entre Toledo y el Duero.

Los mudéjares también se detectan en la construcción cordobesa del momento (Alcázar, reparación de murallas, reformas en la Mezquita-Catedral) (6), ejerciendo de albañil o cantero, a veces en conjunción con maestros cristianos como en la Torrefortaleza del Carpio (h. 1325-28) (7). Sin embargo, en general su peso en el sector de la construcción local debió ser muy limitado, si atendemos a los estudios demográficos y socioeconómicos de la época, que no detectan una amplia base poblacional musulmana en los territorios andalusíes reconquistados. Además el dominio de técnicas y formas tradicionalmente llamadas mudéjares no debe considerarse como una prueba de su intervención. Las cubiertas lígneas, tan características de la construcción andaluza posterior, debieron formar parte del bagaje común de cristianos y musulmanes. También motivos ornamentales supuestamente 


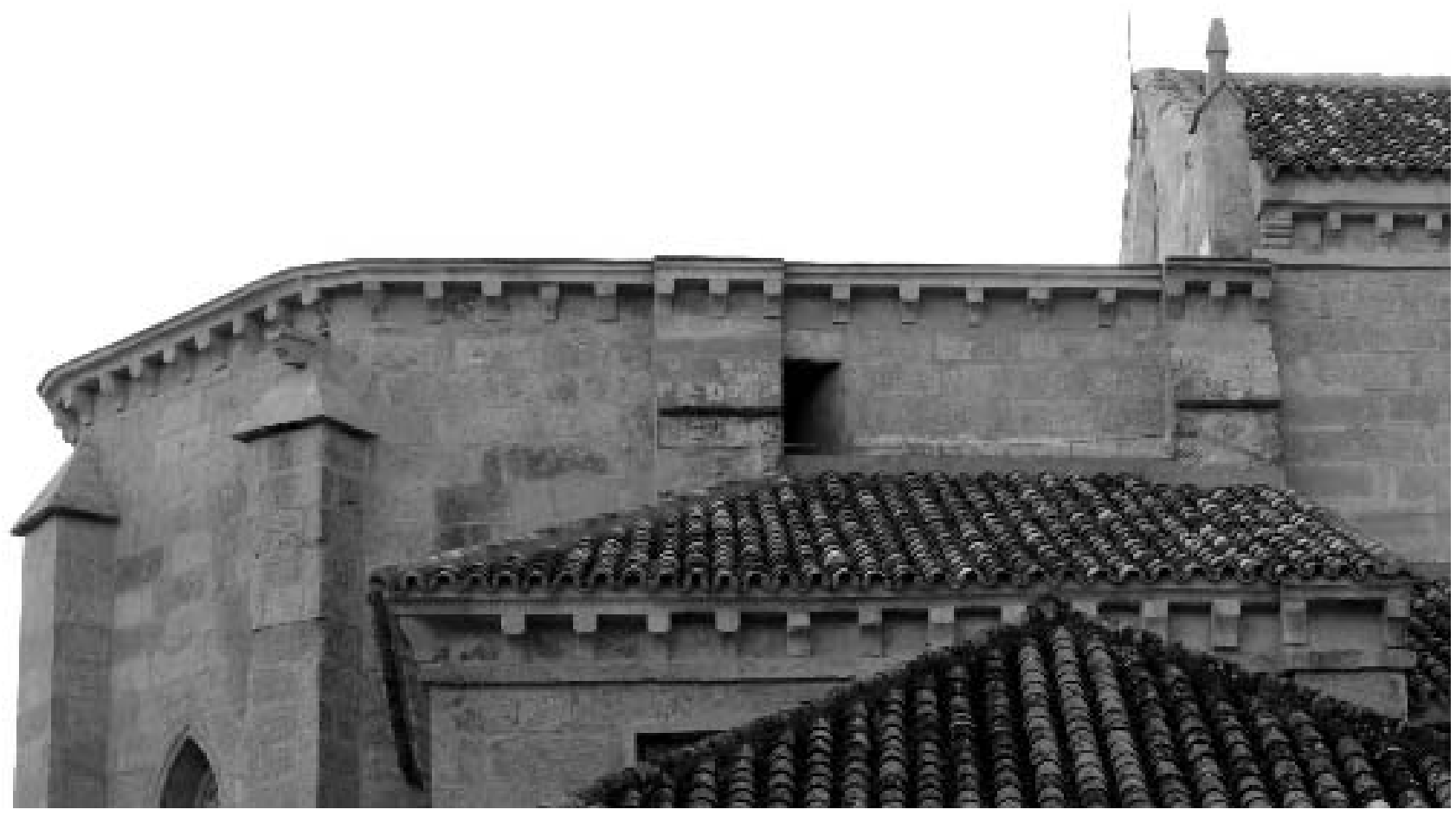

islámicos, obedecen a cierta contaminación visual que siglos de convivencia en la península hace inevitable; como ha señalado Ladero (8), tanto hispano-cristianos como mudéjares participaban de un mismo fondo étnico y cultural remoto que explica muchas analogías.

\section{LOS MUROS EN EL CONJUNTO DEL SISTEMA PORTANTE}

Más que una descripción exhaustiva de la resolución constructiva de las iglesias, se va a prestar atención a cómo el sistema de muros, que junto con los pilares son la estructura portante vertical más importante del edificio, se integra en el conjunto. Muros absidiales y perimetrales de las naves, y las dos grandes arquerías interiores, eran los elementos conformadores de la planta del edificio, y los que inevitablemente debían levantarse en primer lugar. Tanto de los muros, que posteriormente se analizan exhaustivamente, como de los pilares y los contrafuertes absidiales, se ha realizado un estudio constructivo a partir de toda la información disponible, incluyendo el análisis de los paramentos visibles (figura 6, pág. siguiente ).

Las cabeceras son el conjunto constructivo más sólido y mejor trabado. Las bóvedas enlazan con las cabezas de los muros, que así no quedan sueltas, a la vez que la yuxtaposición de capillas favorece el equilibrio y contrarresto de los empujes, afianzándose además el muro perimetral con contrafuertes. Todo esto permitirá construir una estructura portante vertical bastante estable, obteniéndose unos muros absidiales más delgados que los del resto del edificio. Éstos coincidirán con el resto en su resolución constructiva, dos hojas de unos $40 \mathrm{~cm}$ que confinan un relleno.

Los contrafuertes de estos ábsides son modestos, pero han resultado suficientes ante las moderadas luces de los espacios a cubrir, ya que ni en las capillas mayores se Ilegan a superar los ocho metros. Salvo un leve incremento de resalte en el tercio inferior, mantendrán su sección en toda la altura. Se trata, sin embargo, de elementos que dejan entrever las dudas de sus constructores, dada su gran dispersión dimensional o incluso, ocasionalmente, el mal direccionamiento en relación al empuje. Su despiece exterior tiene una traba sencilla $y$, salvo los de S. Pedro obtenidos íntegramente con sillería, estamos ante una cáscara pétrea de en torno a 20-22 cm, que aloja una mezcla de mortero y ripios; la técnica es análoga a la usada para los muros, aunque el paramento de piedra es ahora más delgado. Esta solución permitió dimensionar con flexibilidad el ancho del contrafuerte, con sólo variar el espesor del relleno interior.

Las naves son un cuerpo arquitectónico más inestable, dada su esbeltez y el poco peso y arriostramiento de las cubiertas. Su formalización es sencilla, un gran cajón mural dividido en tres naves por dos arquerías apuntadas. Éstas tienen un fuerte entendimiento longitudinal, sin la sectorización que hubiera supuesto la cobertura con tramos de bóvedas, 


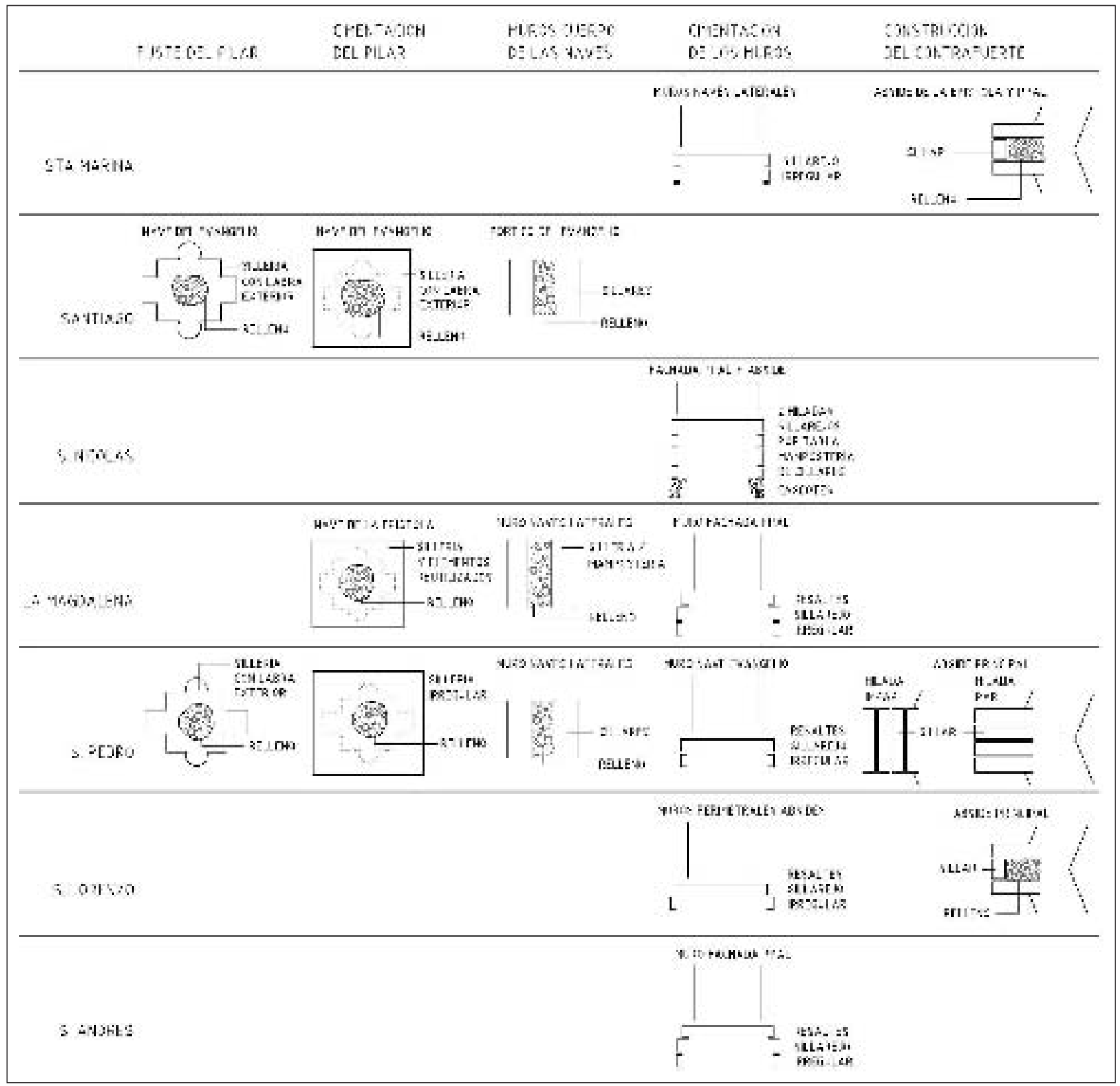

6. Soluciones constructivas detectadas en distintos edificios para pilares, muros y contrafuertes. sustituidas por una larga e indiferenciada techumbre de madera. Los muros perimetrales son masivos, perforados con estrechos huecos abocinados, sin articulación formal con el suelo y muy elemental en coronación: interiormente unas molduras semicirculares, y por fuera ménsulas en cuarto de círculo, que sustentan una tímida cornisa. Se obtienen con dos paramentos de entorno a $40 \mathrm{~cm}$, con un relleno cuyo espesor varía según el grosor total del elemento a construir.

Los pilares se formalizan como un núcleo cuadrado, con semicolumnas adosadas en la dirección del pórtico y pilastras en la otra, mejorando así la rigidez y precaria estabilidad del pórtico ante vuelco lateral. Su formalización, pues, es extremadamente sencilla, quedando el soporte desprovisto de las cualidades estéreas que le hubieran otorgado las articulaciones formales necesarias para recoger los nervios de una bóveda. Esto, en cambio, le permite integrarse con comodidad y gran lógica arquitectónica en la acentuada direccionalidad de la arcada (figura 7).

El estudio realizado para S. Pedro detecta un perímetro de sillares de arenisca labrados exclusivamente al exterior, alojando un conjunto de escasa compacidad constituido por un mortero de cal con trozos de piedra y bolos (9). Esto parece lo habitual, a juzgar por los despieces visibles, y ha sido comprobado, por ejemplo, en el derrumbe de Santiago. Aquí el cimiento es sensiblemente cuadrado $y$, sorprendentemente, tampoco se cuaja con sillería toda la sección, cuyo 
núcleo vuelve a ser un relleno poco cualificado (figura 8). Estas soluciones constructivas debieron motivar más pronto que tarde patologías: desvinculación mecánica entre la cáscara pétrea y el relleno, arenización de éste, humedades por capilaridad en el fuste que debilitan piedra y soporte, etc. Se sabe ya de actuaciones en el s. XVI en los pilares de S. Pedro o Santa Marina, y en las restauraciones abordadas en las últimas décadas están siendo frecuentes refuerzos para subsanar colapsos por aplastamientos del fuste, o asientos diferenciales (10). Las arcadas, por último, más bien parecen un muro armado románico, doblado, y ligeramente adelgazado. Sin embargo sus arcos se apuntan y el conjunto incrementa su altura en lo posible para dar verticalidad al espacio. Su construcción es análoga a la del resto de muros, reduciendo lo necesario el espesor de los paramentos pétreos para obtener un elemento constructivo que, al carecer de bóvedas superiormente, depende extraordinariamente del arriostramiento que proporciona en coronación la armadura de par y nudillo.

\section{TÉCNICAS CONSTRUCTIVAS Y MATERIALES DE LOS MUROS. ESPECIFICIDADES Y ANTECEDENTES LOCALES}

Se van a analizar los tres grandes tipos de muros que constituían el arranque de la fábrica en superficie: absidiales, laterales de las naves y el del hastial principal. Salvo excepciones, dentro de un mismo edificio su resolución constructiva va a ser prácticamente idéntica en los tres tipos, solventando la diferencia de espesor con la variación en la potencia del relleno interior; esto posibilita su descripción constructiva de manera conjunta.

La piedra utilizada es una arenisca frecuente en las cercanas estribaciones de Sierra Morena, y ha sido analizada en detalle para algunas obras como las de restauración de S. Pedro. Aquí, por testigos extraídos en abril de 1991, se define como procedente de "rocas areniscas porosas constituidas por una matriz silícea (arenas) unida por una fracción cementante de material calizo, y

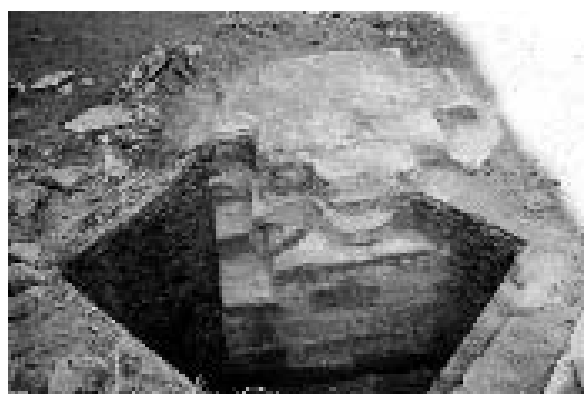

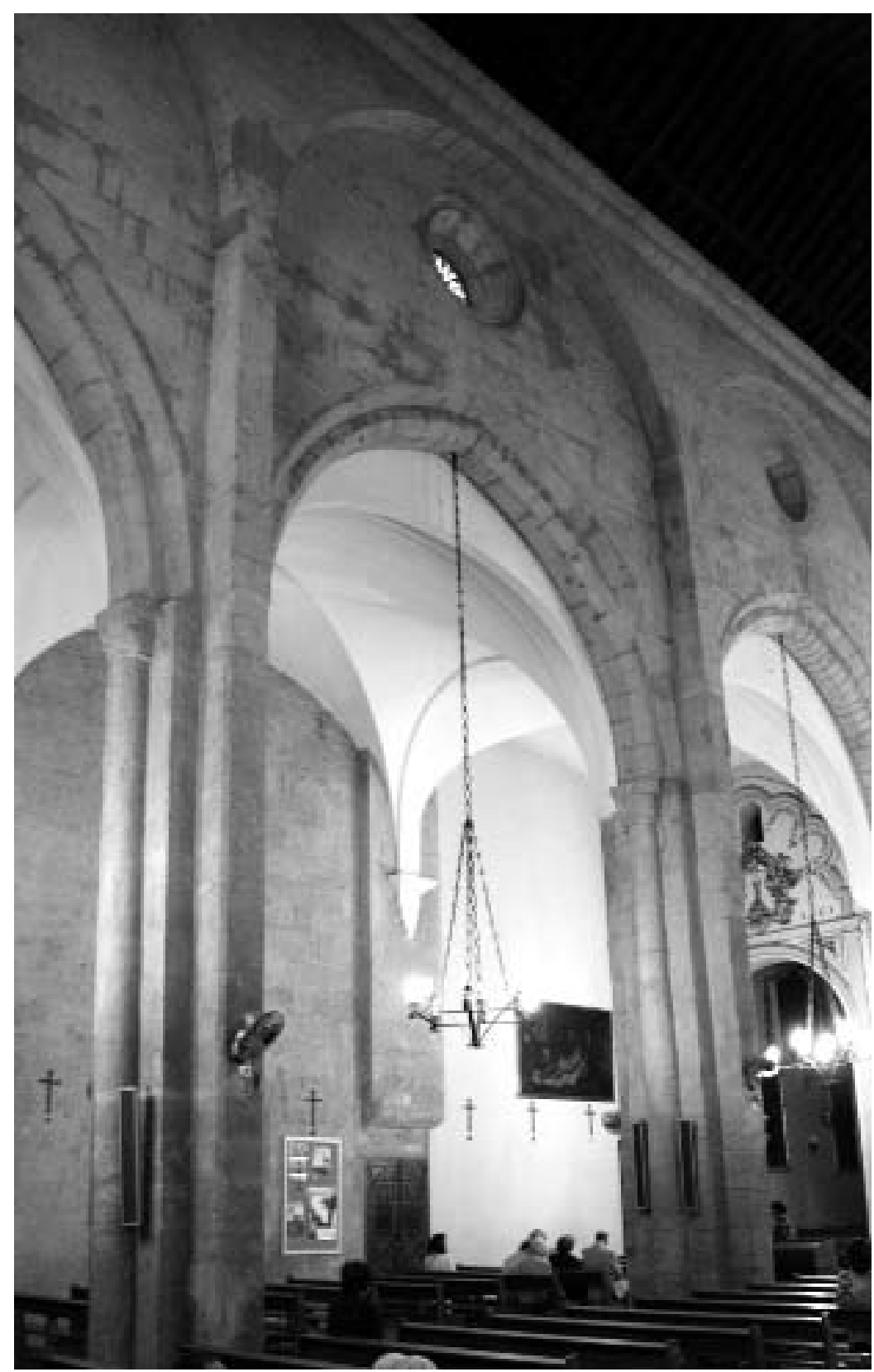

con una importante componente fosilífera" (11). Los sillares tendrían un ajuste posterior a pie de obra, ya que bajo el pavimento de algunos templos, S. Pedro o La Magdalena, se han hallado picaduras de arenisca; en el primero forman parte de rellenos apisonados

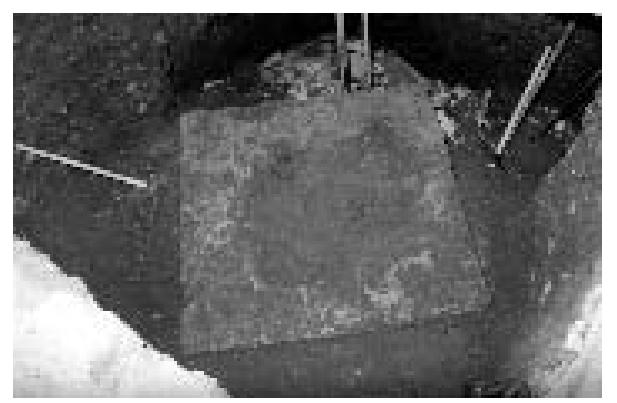

7. S. Miguel: pilares y arcada.

8. Santiago: Pilar y su cimentación (año 1988) 


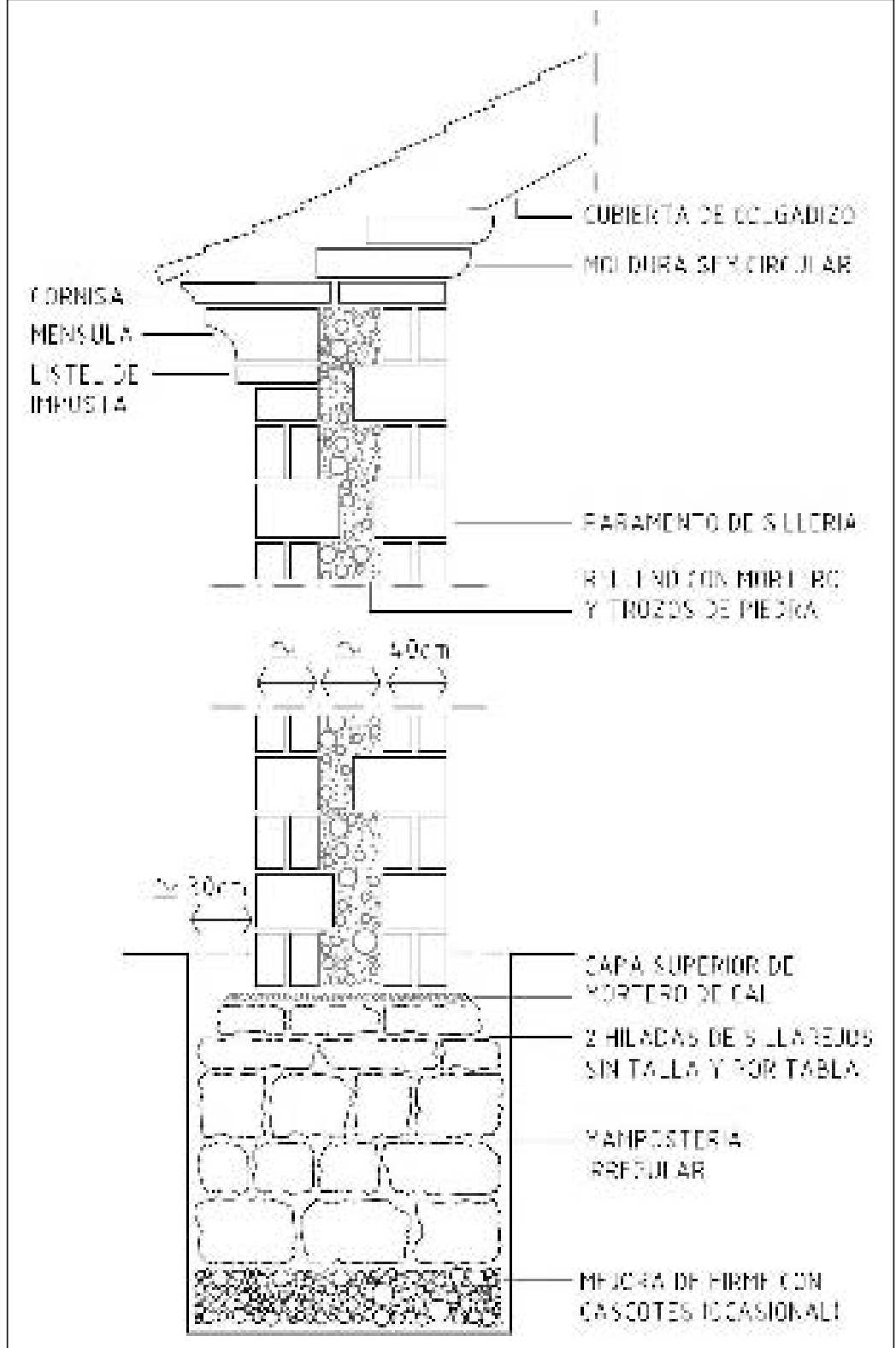

9. Sección constructiva "tipo" de muro de nave lateral. y que alcanzan la considerable potencia de $1,20 \mathrm{~m}$.

La masa mural esta constituida íntegramente por sillería y, a diferencia de los antecedentes islámicos, rara vez nos encontramos con elementos significativos reutilizados; excepcional y únicamente se utilizaron algunas columnas monolíticas de mármol en los arcos torales de las cabeceras (S. Pablo y S. Lorenzo). Tanto en las catas murales extraídas para el citado estudio de S. Pedro, y sus posteriores obras de emergencia (1993) (12), como en los derrumbes generales de La Magdalena (1990) y Santiago (1988) (13), se detectan los dos paramentos de sillería ya comentados para cada uno de los tipos de muro, confinando un relleno de mortero y trozos de piedra. Esta fábrica mixta de tres hojas es una característica común con las construcciones góticas contemporáneas, demostrando la independencia respecto a la manera de aparejar las piezas y el formato de éstas, aspectos que en Córdoba tendrán importantes particularidades (figura 9).

El despiece de los paramentos varía de unas construcciones a otras (figura 10). Salvando algunas zonas de mampostería, detectables en La Magdalena (14) y S. Lorenzo, con carácter general se pueden establecer dos grandes modalidades. La de traba convencional utiliza un único tipo de sillar de dimensiones moderadas, y colocado con juntas verticales alternantes entre hiladas; las piezas no suelen superar los $70 \mathrm{~cm}$ de longitud, siendo lo más habitual entre 40 y $50 \mathrm{~cm}$, y con una altura de $30-40 \mathrm{~cm}$. Será el adoptado por los edificios más antiguos de la ciudad, el templo conventual de S. Pablo y la parroquia de La Magdalena (figura 11).

Sin embargo son más frecuentes los lienzos que alternan una soga con un tizón, recurriéndose a sillares bien trabajados e inusualmente grandes en el contexto peninsular, donde prosiguió la tendencia reductora iniciada siglos antes (15). Incluso en la importante Catedral burgalesa, con la que tantos vínculos se han establecido, las longitudes no suelen sobrepasar habitualmente los $60 \mathrm{~cm}$, con alturas de 26 a $40 \mathrm{~cm}$ (16). En cambio los muestreos realizados en las fábricas de S. Miguel, S. Lorenzo, Santa Marina, S. Nicolás de la Villa, S. Pedro, Santiago y S. Andrés, establecen como frecuentes para las sogas los 100-110 cm (oscilando generalmente en un intervalo entre 78 y $113 \mathrm{~cm}$ ), para los tizones $20-21 \mathrm{~cm}$ (intervalo 17-30 $\mathrm{cm})$ y como altura de sillares (o de hilada) 40-41 cm (intervalo 32-43 cm).

Para este tipo de despiece, en los casos que se ha podido determinar, el espesor de 40 $\mathrm{cm}$ de cada hoja del muro se obtiene con dos sillares contiguos, trabados por un tizón transversal. Los mismos, al manifestarse en las esquinas, dan la característica duplicidad de tizones, que en definitiva están evidenciando la construcción y espesor de la hoja exterior; presumiblemente la interior sería similar. Tan sólo circunstancialmente por cuestiones de despiece del lienzo se triplica el tizón en la esquina (figura 12).

La solución se hace eco de tradiciones detectadas ya en época romana (17) y generalizadas bajo dominio musulmán (18). Será una señalada característica del grupo parroquial, siendo utilizada poco después en la construcción del nuevo Alcázar cristiano (h. 1328), y perpetuándose durante el resto del bajomedievo cordobés tanto en edificios religiosos como civiles; esto la convertirá en un señalado localismo constructivo, no 


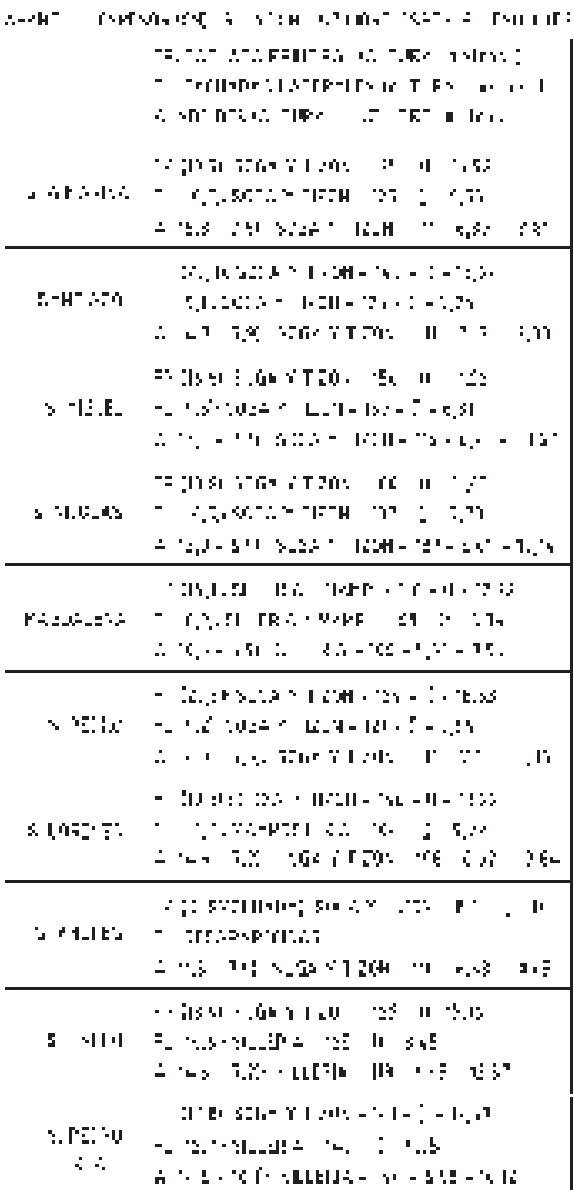

detectable en otras iglesias del alfoz cordobés, ni tampoco con carácter general en la arquitectura coetánea andaluza. El alzado de los lienzos nos recuerda más a los muros islámicos de la ciudad que a los de los templos cristianos de la meseta, con una simple traba de juntas verticales alternantes.

No obstante, existen sustanciales diferencias con las técnicas islámicas, ya que al menos en las grandes construcciones de la ciudad, la soga se alterna con dos o más tizones, según la época, para construir íntegramente con sillería un muro macizo (19). Será excepcional que el tizón sea único, algo sólo detectable en la primera arquitectura de etapa emiral, como las partes más antiguas de la Mezquita aljama (s. VIII); posteriormente, como han señalado numerosos autores (20), los despieces islámicos evolucionarán aumentando el número de sillares atizonados a la vez que se reduce su anchura (figura 13).

En cambio en los lienzos parroquiales la norma es la alternancia de la soga con un solo tizón, con la excepción comentada de las esquinas, y el muro no es macizo como el islámico. También hay que tener en cuenta que los sillares atizonados no resuelven todo el espesor del lienzo, sirviendo tan sólo
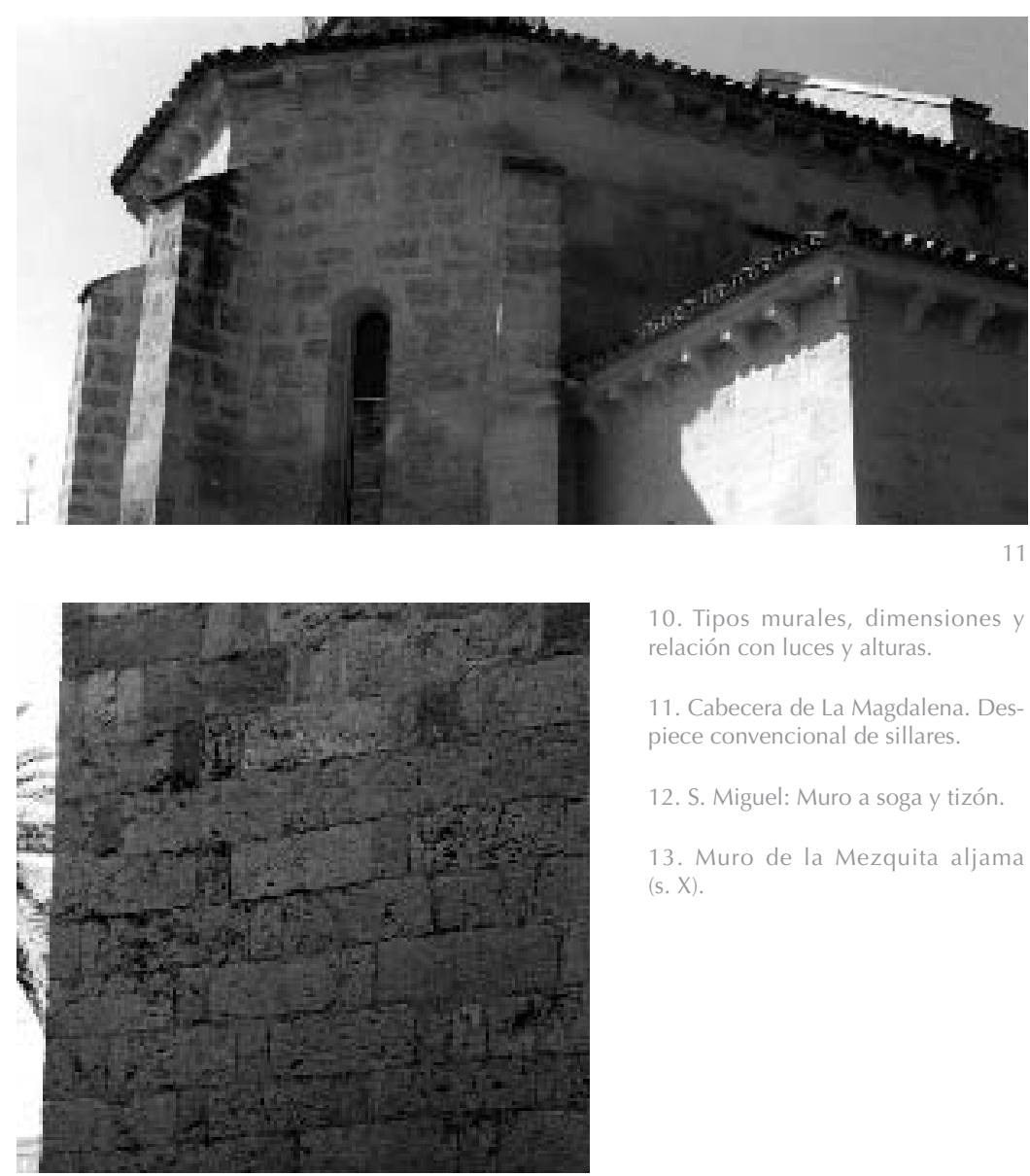

10. Tipos murales, dimensiones y relación con luces y alturas.

11. Cabecera de La Magdalena. Despiece convencional de sillares.

12. S. Miguel: Muro a soga y tizón.

13. Muro de la Mezquita aljama (s. X).

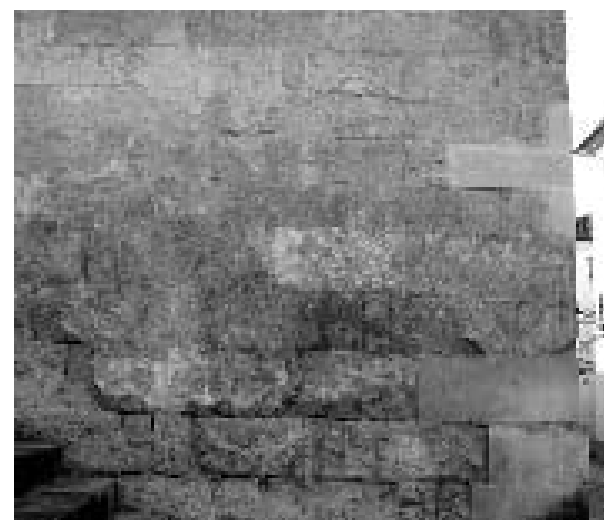

para trabar los dos sillares contiguos a soga y solidarizar mecánicamente con el relleno interior. Muchos de los muros superan los $120 \mathrm{~cm}$ de espesor, Ilegando algunos hasta los $150 \mathrm{~cm}$, por lo que hubieran sido necesarias unas piezas excepcionalmente grandes, y las sogas medidas en los paramentos son inferiores a $110 \mathrm{~cm}$ (figura 14, pág. siguiente).

Los parecidos se deben al probable reaprovechamiento del sillar islámico, una hipótesis coherente con la similitud que presentan los formatos utilizados en ambos casos. Los autores que estudian la producción islámica local establecen como habituales $70-110 \mathrm{~cm}$ 
para las sogas, $20-25 \mathrm{~cm}$ para los gruesos del tizón, y 35-42 cm para la altura de la pieza (21); se trataría, pues, de rangos de valor prácticamente coincidentes con los expuestos para las iglesias. Dada la premura en construir éstas y lo limitado de los recursos, gran parte del volumen pétreo pudo obtenerse de la reutilización de sillares de los grandes edificios del califato. A mediados del siglo XIV está documentado que la construcción de la cabecera de S. Hipólito se abastece de sillares de la vieja ciudad palatina de Medina Azahara, conocida entonces como Córdoba la Vieja; ésta había sido cantera de la ciudad desde su destrucción a principios del siglo XI (22). Otras veces pudieron provenir de las propias mezquitas de barrio, y que ya desde época islámica, en caso de abandono, se expolian (23); también algunas, ya bajo dominio castellano, se desmontan para reocupar los solares con la fábrica de una iglesia (S. Lorenzo y Santiago). Independientemente del despiece utilizado, las piezas se colocan sobre un lecho de mortero de cal, con una llaga entorno a 1 ó $2 \mathrm{~cm}$. Los estudios de Félix Hernández (24) diferencian este mortero
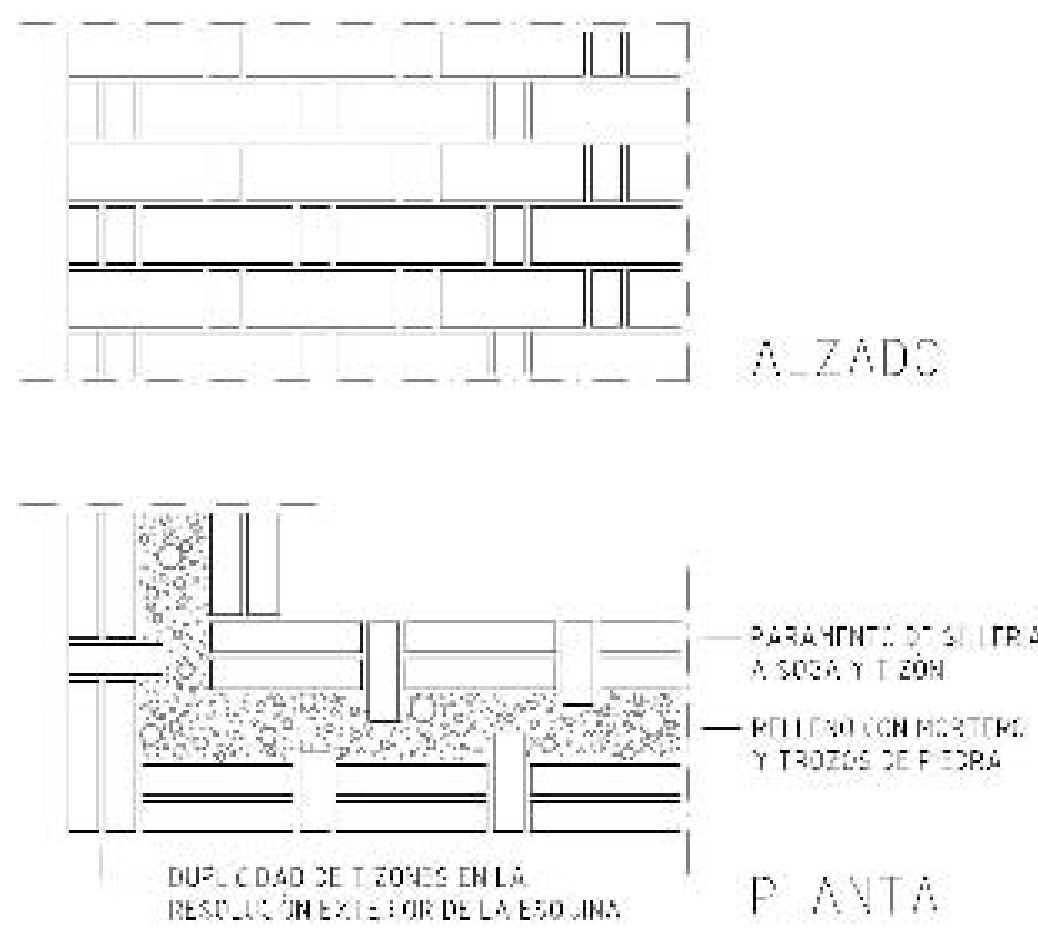

14

14. Solución constructiva de muro a soga y tizón en las iglesias cordobesas. cristiano, que no supera la relación 1:1 entre cal y arena, del de los edificios islámicos de la ciudad, más rico en aglomerante. En las juntas tanto verticales como horizontales se introducen guijarros de río con forma de laja, una práctica habitual en la construcción de sillería, y que en Córdoba cuenta con el importante antecedente islámico (25). Sirven no solo para el nivelado y asentado de los sillares, sino también para que el peso de los mismos no evacue la mezcla mientras fragua.
Algunos autores sostienen además que estas llagas de mortero facilitan la unión y homogeneidad de asentamiento con el habitual relleno interior del muro (26).

La cimentación de los muros, en zanja corrida, sólo se ha podido reconocer exhaustivamente en contadas ocasiones. En La Magdalena (27) y S. Pedro (28) existen trabajos arqueológicos y catas específicas; S. Nicolás (29) sufrió una importante obra de recalce y es registrable en una cripta funeraria (figura 15); también el afloramiento parcial, a veces por obras, permite verificar la solución en S. Lorenzo (ábside norte), Santa Marina (muros de la nave y ábside norte) y S. Andrés (fachada principal). La cota de apoyo se detecta en S. Nicolás a 3,50 m de profundidad, aunque el primer metro y medio es sólo una mejora de firme con cascotes apisonados, para arrancar desde ahí con el verdadero sistema de cimentación. Éste es en la mayoría de los casos más superficial, en $\mathrm{S}$. Pedro a 1,5 m, o en La Magdalena rondando a lo sumo los $2 \mathrm{~m}$ de profundidad.

Habitualmente se trata de una mampostería poco organizada de sillarejo irregular, sin talla, con recalzos en las juntas consistentes en piedras de pequeño tamaño y cantos rodados; está coronada y regularizada por dos hiladas de piezas de tendencia alargada y plana, dispuestas por tabla, y cogidas con mortero de cal. Finalmente, una fina capa de mortero serviría de terminación y regularización superior, ofreciendo un soporte adecuado para el replanteo de los muros; podría entenderse como una versión modesta de las solerías perdidas que para tal fin se han detectado en grandes edificios góticos, como la Catedral de Sevilla (s. XV) (30). Respecto a los paramentos de los muros, la cimentación tiene un retallo de 20 ó $30 \mathrm{~cm}$, formalizado con el sucesivo avance de las dos hiladas superiores; al ancho obtenido presumiblemente se mantendría constante en profundidad (figura 16). Esta cimentación también tiene sustanciales diferencias con la islámica, que en amplias zonas de al-Andalus arranca con una hilada constituida íntegramente por sillares atizonados, siendo además en Córdoba una solución característica (31). Inferiormente podemos encontrar una base de mampostería, como en la mezquita califal de El Fontanar, o incluso guijarros de río a espiga, frecuentes por ejemplo en las edificaciones (mezquita, baños...) del arrabal aparecido en el año 2002 al oeste de la ciudad, durante las obras de una ronda urbana (figura 17).

Por último, y considerando la cronología de los edificios, parece que la "fábrica cristiana convencional" (dos hojas con juntas verticales alternantes y relleno interior) sería la solu- 
ción pionera en la ciudad, contaminándose o adaptándose después a las circunstancias locales (material disponible y su formato, aprovisionamiento, etc.). El aparejo a soga y tizón se generalizaría, no sólo por el conocimiento directo de las fábricas islámicas, sino también por la amplia disponibilidad de sillares ya elaborados; sin embargo, este nuevo despiece, no alteraría la solución del muro mixto gótico, que mantiene el resto de sus características. Tampoco hace imprescindible la intervención de maestros islámicos, escasos si tenemos en cuenta los indicios demográficos, y que difícilmente hubieran tenido un mínimo protagonismo en unos edificios cuya tipología, formas e incluso características constructivas son claramente cristianas.

\section{DIMENSIONAMIENTO DEL SISTEMA DE MUROS DEL EDIFICIO}

El espesor de cada uno de los tipos fundamentales de muros estudiados, absidiales, laterales de las naves y hastial principal, se mueve dentro de valores similares, con independencia del edificio al que pertenezcan. Esto permite suponer la existencia de criterios, posiblemente de fuerte componente empírica, para enfrentarse al dimensionamiento de los elementos. Éste, además, se realizaría del fuste de los elementos estructurales, obviando aspectos formales como basas, molduras, etc.; también las cimentaciones se entenderían como un recrecido o retallo del elemento que reciben, algo coherente con su pobre formalización constructiva. Es un criterio bien documentado luego en el tardogótico español; por ejemplo, el maestro Enrique refrenda así la dimensión dada en la traza a los pilares de la catedral de Segovia: “... treze pies de grueso en el byvo syn la salida de las sotobasas" (32).

Más que la propia resistencia mecánica del elemento o del material, los aspectos de geometría y proporción eran los determinantes en el éxito del equilibrio estructural del conjunto (33). También se trata de un proceder recogido tardíamente en los tratados de arquitectura del XV y aún del XVI, asumiendo en cierta manera los empíricos procedimientos del constructor medieval, que se habrían demostrado como suficientes; así, por ejemplo, se dimensionan espesores de pilares o muros en relación a su altura o de la luz del espacio a cubrir.

Por todo ello, principalmente se ha realizado un análisis de las dimensiones de los muros y de sus características geométricas; serán de importancia tanto la sección típica del fuste como la relación entre su altura y espesor (esbeltez) o la existente entre dicho espesor
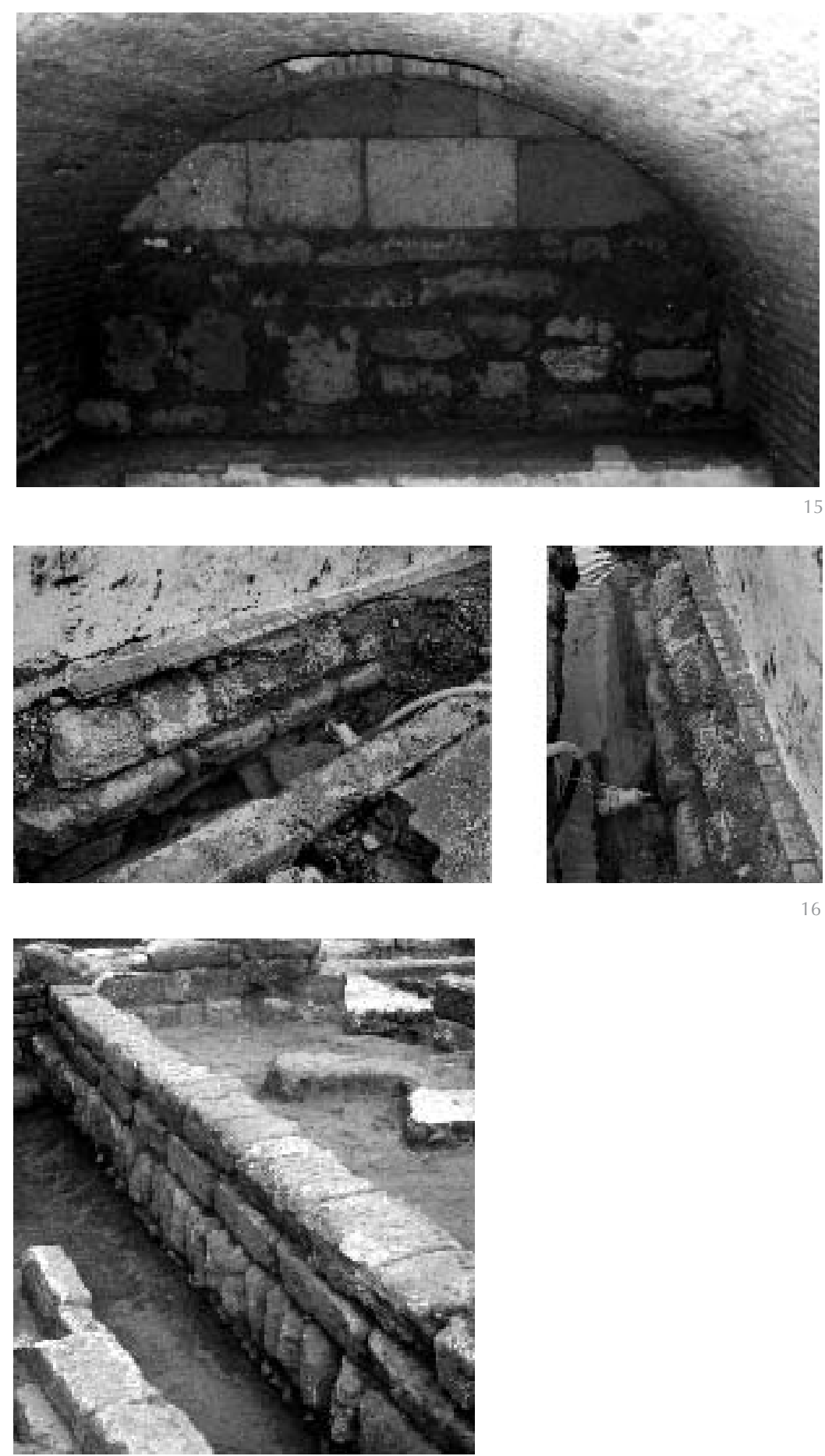

y la luz libre del espacio que conforman, en el caso de estar abovedados como las capillas de las cabeceras. La medición de las secciones típicas de los distintos tipos de muros, sus características dimensionales, y las principales relaciones comentadas, se recogen en la tabla de la anterior figura 10.

Los del hastial de los pies son los más gruesos, y obviando valores extremos, se opta habitualmente entre dos rangos de medidas, el intervalo $141-150 \mathrm{~cm}$ o en torno a los 125 $\mathrm{cm}$, en este caso igualando a los costados. En los muros de éstos, los de las naves laterales,
15. Cimentación de muro en S. Nicolás (año 1997).

16. S. Andrés: Retallos con doble hilada en parte superior de cimentación (obras de 1997).

17. Cimentación islámica (exc. 2002) 
la dimensión más frecuente oscila entre 121 y $125 \mathrm{~cm}$, adelgazándose para S. Lorenzo (104 $\mathrm{cm})$ y La Magdalena $(108 \mathrm{~cm})$, e incrementándose al entorno de $140 \mathrm{~cm}$ en S. Nicolás y S. Pedro el Real o los $150 \mathrm{~cm}$. de S. Miguel; éste conformará todo el perímetro de naves con este desmesurado valor.

En un mismo edificio todos los lienzos de la cabecera mantienen el espesor, incluyendo los separadores de capillas. Son comparativamente los más delgados de las iglesias: salvo los casos de S. Nicolás $(137 \mathrm{~cm})$ y S. Pedro el Real (144), para los ocho restantes oscila dentro del intervalo $106-119 \mathrm{~cm}$, con preferencia por los 110-111 cm. La relación entre estos espesores murales y la anchura de los ábsides que conforman es bastante conservadora: para la capilla mayor, la más ancha, el cociente entre la luz libre y el ancho del muro absidial sobrepasa escasamente a siete (S. Pedro y Santiago), descendiendo hasta los cinco de $S$. Nicolás. Pese a que algunos edificios igualan muros con distinta altura y circunstancias mecánicas, existe una gradación lógica en el espesor de estos elementos: absidiales, naves laterales y hastial principal. Se incrementaron los que iban a alcanzar mayor altura, intentando limitar una esbeltez que, no obstante, acabará siendo mayor en los lienzos más altos: en una horquilla entre $6,31-9,22$ para los de las naves laterales, 9,95-13,84 en los absidiales, y 11,22-16,53 para el muro piñón de los pies.

En estas cuestiones también podían incidir los sistemas metrológicos al uso, útiles para la generación de un patrón métrico de referencia para cada obra concreta, la virga o vara de medir (34); ésta serviría para establecer los múltiplos y submúltiplos necesarios para el dimensionamiento y métrica de la fábrica. Anteriores estudios sobre el trazado de las plantas parroquiales han permitido establecer hipótesis fundadas sobre sus mecanismos de composición y control formal (35), en los que tuvo un papel importante como referente métrico la vara de Burgos o castellana, equivalente a $83,59 \mathrm{~cm}$; sus submúltiplos más habituales eran el pie (tercio de la vara, 27,86 $\mathrm{cm}$ ) y el palmo (la cuarta parte, 20,89 cm). La adopción de este sistema metrológico es coherente con los vínculos que insistentemente se han establecido a nivel arquitectónico con los talleres burgaleses: con ellos podría haber viajado al sur la unidad de medida local.

Un testeo con esta unidad de medida permite comprobar cómo muchos de los muros de las naves laterales prácticamente se ajustan a una vara burgalesa y media (ó 4,5 pies), cuantificable como $125 \mathrm{~cm}$ (Sta. Marina, Santiago, S. Pedro y S. Pablo). Este espesor se suele incrementar para el hastial principal en un pie más, hasta rondar los 150 cm (Santiago,
S. Miguel, S. Nicolás, S. Lorenzo y S. Andrés), minorándose en los ábsides hasta los cuatro pies $(112 \mathrm{~cm})$ (Sta. Marina, Santiago, S. Miguel, S. Pedro y S. Andrés). En cambio los codos islámicos, fehacientemente detectados en Córdoba (36) en el caso del rassasi $(58,93 \mathrm{~cm})$ y el mamuni $(47,14 \mathrm{~cm})$, no explican fácilmente estos valores; se aleja así, también desde este punto de vista, la hipótesis de la participación mudéjar o islámica en el proceso constructivo.

\section{APLICACIONES PARA EL CONOCIMIENTO DE LAS FÁBRICAS Y SU PROCESO CONSTRUCTIVO}

La objetivación de la técnica constructiva de los muros ayuda a interpretar con mayor rigor algunos restos que nos han Ilegado. Es el caso de S. Andrés, un templo parroquial coetáneo a los estudiados, y que en el s. XVIII es reedificado en el mismo lugar, subsistiendo marginalmente en la nueva iglesia su capilla mayor y la fachada principal de los pies. Este muro, aunque reparado, desmochado en altura, y sustituida su portada, permite todavía una adecuada lectura constructiva del despiece. Así, entre otros aspectos, es manifiesta la alternancia original a soga y tizón, duplicando éste en los extremos del lienzo conservado (figura 18). Al ser ésta la solución de esquina característica de este aparejo, es posible determinar que el muro se ha conservado íntegramente en toda su longitud, y que ésta era la anchura total del templo, unos 20,44 $\mathrm{m}$ que se corresponderían con una iglesia de tres naves similar a las estudiadas. Y esto pese a tener por cabecera, anómalamente dentro del conjunto parroquial cordobés, un solo ábside.

En otros casos, podemos obtener datos sobre el proceso constructivo de los muros e incluso del propio conjunto del edificio. Sobre este aspecto se sabe que en la época coexistían diversas formas de proceder: una erección general del conjunto, levantado con cierta uniformidad por hiladas horizontales, algo propio de iglesias pequeñas; o también la priorización de una parte, y que era conveniente en edificaciones de entidad. Autores como R. Cassanelli (37) sostienen que esto último fue además lo que se acabó generalizando en la etapa gótica, ya que desde el siglo XIII se empiezan a abandonar las técnicas de construcción en horizontal en favor de un modo vertical. Esto permitía anticipar el uso de algunas partes del edificio, a menudo la cabecera, que se acabaría completa hasta el nivel de cubierta.

En Córdoba tenemos indicios de los dos planteamientos, quizás por la diferencia de tamaño entre las iglesias, y es algo que 
quedó reflejado en los propios paramentos murales. En La Magdalena, quizás la primera iglesia de la ciudad y la más pequeña entre las estudiadas, un zócalo de sillares recorre el edificio tanto en su paramento exterior como interior, con piezas además cambiantes de formato en cada hilada. Resuelven el primer metro y medio aproximadamente de las naves, para luego servir de apoyo a una mampostería más modesta. Aunque cuando avanzara la obra se diversificaran los tajos, parece que en una primera etapa constructiva se está acometiendo simultáneamente, si no todo el edificio, al menos sí el muro exterior (figura 19).

Sin embargo, en muchos otros casos se detectan anomalías que apuntan a una manera de proceder diferente, priorizando ante todo la construcción de la cabecera. Así, en el encuentro entre ésta y cuerpo de naves no es raro encontrar fracturas, retallos, adarajas, discontinuidad de hiladas horizontales, inconsistencias formales, etc. S. Lorenzo tiene una cabecera de sillería a soga y tizón en toda su altura, enlazando con unas naves cuyos muros laterales son de mampostería, un cambio de material que denota de por sí un entendimiento autónomo. En el encuentro, además, se produce un estrangulamiento, al reducir las naves su anchura respecto a la primera. También en la propia cabecera triabsidiada pudo acabarse previamente la capilla mayor, que dejó unas visibles adarajas en su muro norte para un futuro enlace con el ábside lateral, con el que ni tan siquiera se mantiene la concordancia de hiladas (figura 20, pág. siguiente).

Igualmente en Santa Marina tenemos indicios de una construcción discontinua, que adelantaría la completa ejecución de la cabecera. Junto al cambio en el diseño de las ménsulas, de modillones de rollos en las capillas absidiales y de cuarto de círculo en las naves, en el costado norte se aprecia la torpe unión de ábside y nave: es significativo que la cornisa de ésta apoye en la de la capilla, que forzosamente sería anterior; también la falta de continuidad en el Ilagueado horizontal; y, por último, que el enlace se realice con un tramo de paramento curvo, forzado por desajustes en las alineaciones de los respectivos tajos de obra (figura 21, pág. siguiente). También en esta iglesia es posible conocer cómo la nave mayor avanzó en su construcción, con toda su altura, desde los pies a una cabecera totalmente terminada. Una interrupción de los trabajos produjo en las partes altas de la nave mayor un cambio en la sección del muro, un salto en la cornisa, y las consiguientes adarajas escalonadas (figura 22, pág. siguiente). En los templos conventuales, notablemente más ambiciosos en tamaño y entidad arquitectó-
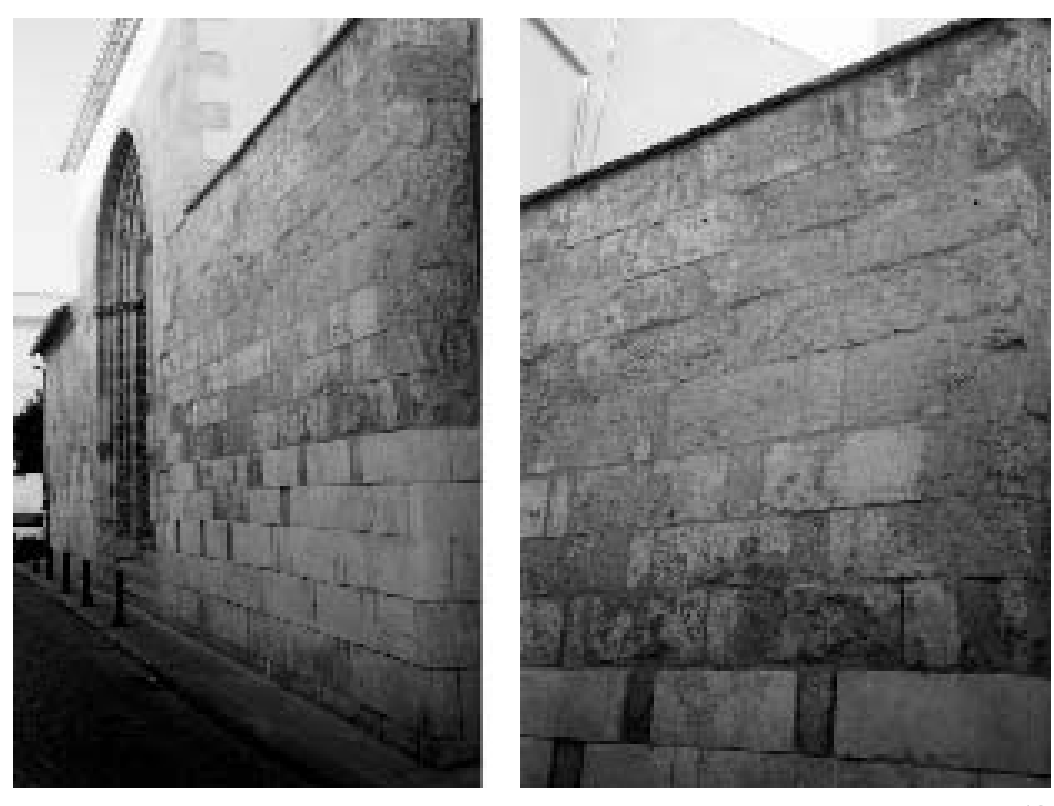

nica, la priorización de una parte es también lo habitual. El templo de S. Hipólito, algo posterior a la etapa estudiada, a mediados del siglo XIV sólo levanta la capilla mayor y crucero, todo con bóvedas de crucería, realizándose la nave ya en el siglo XVIII. Parecido planteamiento pudieron tener los de S. Pablo y S. Pedro el Real, aunque ahora las obras se terminan en la propia época medieval. Se comienzan a erigir con sillería convencional por sus cabeceras, completándose la fábrica con este aparejo salvo las fachadas de los pies; aquí aparece el despiece a soga y tizón, contagiándose de lo que ya debía ser general en la ciudad, y que persistió durante toda la etapa bajomedieval.

\section{CONCLUSIONES}

El sistema mural diseñado atendió a la necesidad de edificios ágiles de ejecución y económicos, integrándose adecuadamente en el conjunto arquitectónico. En Córdoba,

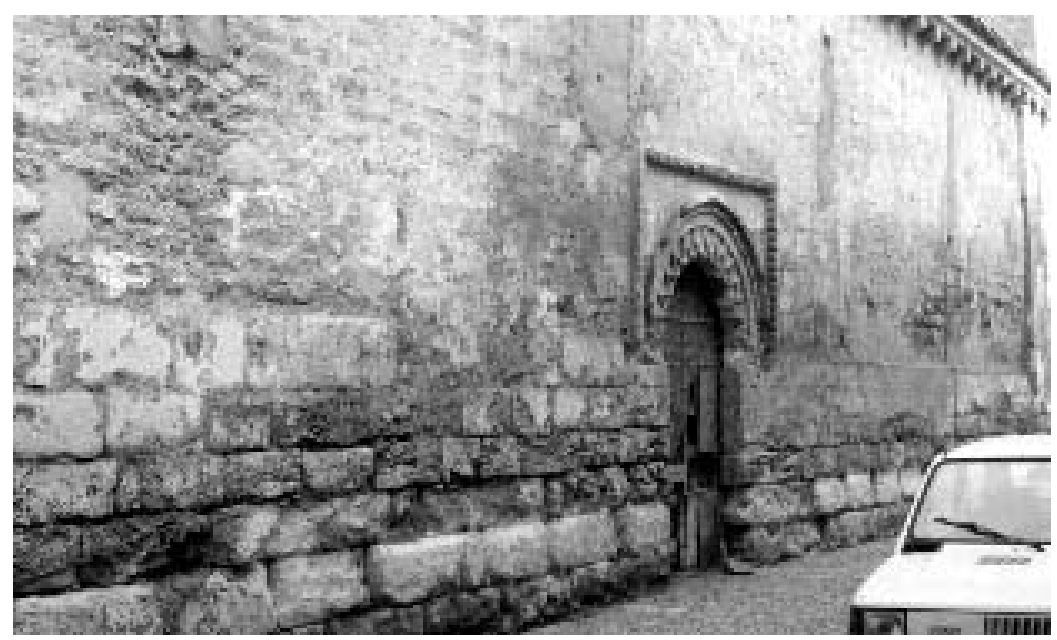

19 
20. Adarajas en S. Lorenzo.

21. Sta. Marina: enlace de capilla y nave lateral.

22. Sta. Marina: adarajas en nave central.

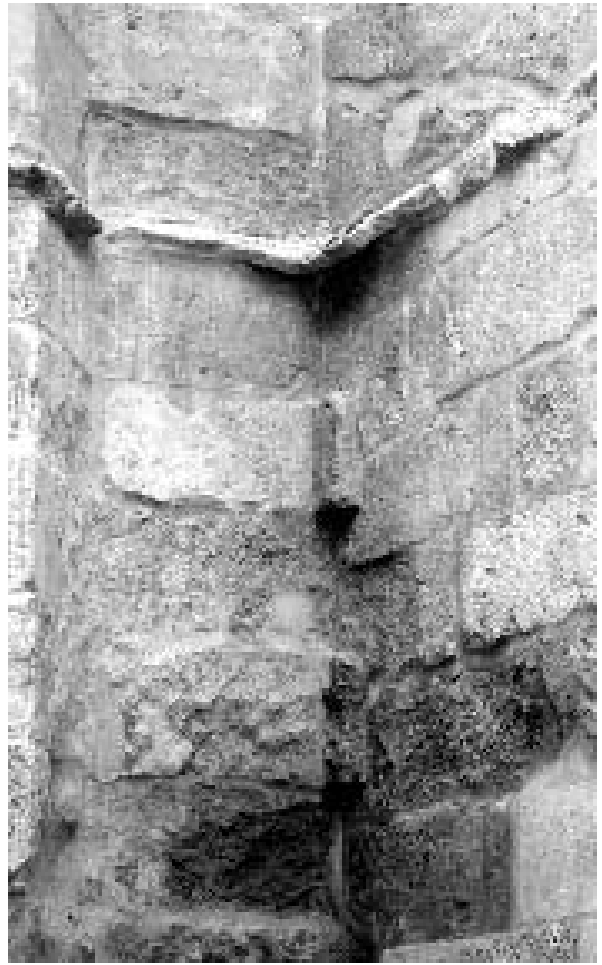

20

el habitual muro de tres hojas gótico, sin perder su esencia, construye sus paramentos pétreos tanto con el habitual despiece de piezas similares y juntas alternantes, como con la combinación de soga y tizón; esto último es, pese a su gran repercusión aparente, tan sólo un cambio epidérmico. Una solución que no supone, además, la participación de maestros islámicos, a la que tampoco apuntan las características de la cimentación, el mortero utilizado, ni otro tipo de indicios, como los metrológicos. Esta disposición a soga y tizón fue la más utilizada, aunque no debió ser la pionera en la ciudad; inicialmente se importarían los sistemas murales convencionales, como es comprobable en los primeros edificios. Posteriormente, las soluciones constructivas se harían eco de las persistentes tradiciones locales, modificando

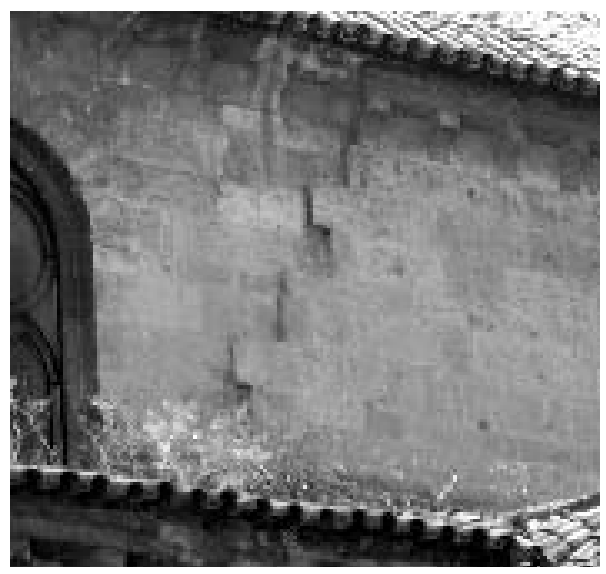

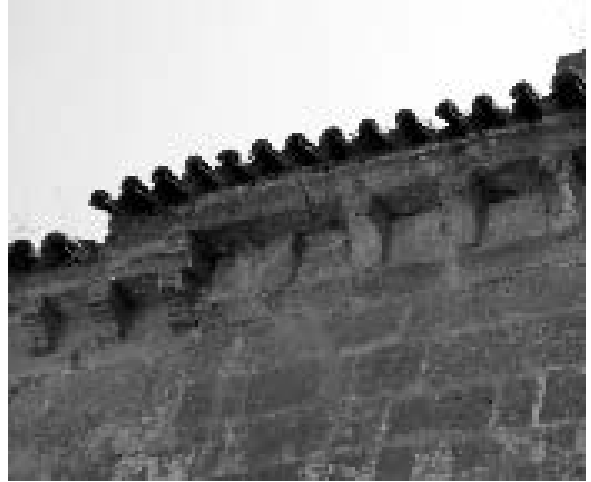

21

el despiece para poder reutilizar los sillares de acarreo de los grandes edificios islámicos, un preciado material ya trabajado y listo para su colocación. Estas consideraciones constructivas y cronológicas aportan una interesante herramienta para conocer el proceso de erección de los muros y el propio edificio, uniéndose a los indicios relativos al formato, juntas horizontales y verticales, adarajas, existencia o no de traba entre paramentos, etc.

El formato del sillar reutilizado, característico por su tamaño y alargadas proporciones, sin embargo no debió influir en la dimensión total del muro, ya que al existir un relleno interior había flexibilidad para asignar espesores a cada tipo. Libres de estos condicionantes constructivos, los maestros góticos debieron operar con ciertas reglas o criterios comúnmente aceptados, aplicables dentro de un rango de luces y cargas. A esto apunta el hecho de que, dentro de todo el conjunto edificatorio estudiado, las secciones resistentes tienen valores típicos o reiterativos. El dimensionamiento resultante, aunque un tanto desmesurado, atiende a la problemática estructural que afecta a cada elemento. Así, en un mismo edificio suele existir una gradación lógica en el espesor de los muros, intentando limitar la esbeltez de los lienzos más altos. Los absidiales son los más delgados, su altura no es excesiva y las bóvedas sujetan en cabeza y contrarrestan entre sí los empujes; tan sólo el perímetro necesitará afianzarse con unos modestos contrafuertes. Consecuentemente, la falta de estabilidad en coronación, justificaría el gran espesor de los lienzos de las naves; las cubiertas de madera eran ligeras y su deterioro podía ser causa de perniciosas fuerzas horizontales. El hastial principal, el lienzo más alto del edificio, será también el más grueso, intentando limitar una esbeltez que, pese a todo, rebasará la del resto de tipos murales.

Es manifiesta la capacidad de los artífices cordobeses para generar soluciones específicas a las necesidades y recursos 
concretos, dotadas a la vez de gran lógica constructiva; serán unas cualidades detectables también en el resto del edificio. Sus conocimientos, posiblemente muy limitados, no le permitirían abordar las grandes estructuras de las catedrales y templos conventuales de la meseta, pero las fábricas ganarán altura para mejorar los pesados edificios románicos y cistercienses. Las primeras iglesias de Córdoba, aun con gruesos muros, cubiertas lígneas en las naves y masivas capillas absidiales, intentarán secundar la sensibilidad del incipiente gótico hispano.

\section{BIBLIOGRAFÍA}

(1) Se agradecen las facilidades prestadas para el acceso y estudio de la documentación del Archivo de la Delegación de Cultura en Córdoba de la Junta de Andalucía. Departamento de Protección del Patrimonio Histórico (autorización de consulta y uso de 28/8/2000, ref. DPI/jvv/tv).

(2) Blanco Roldán, R. "Cubiertas de madera de las iglesias fernandinas de Córdoba". Informes de la Construcción, Vol. 59 no 507 (2007), pp. 33-41. doi: 10.3989/ic.2007.v59.i507.530.

(3) Gómez de Cózar, J. C.; Rodríguez Liñán, C.; Rubio de Hita, P. "Geometrías concertadas. Las cabeceras de las iglesias gótico-mudéjares de la ciudad de Sevilla". Actas del Tercer Congreso Nacional de Historia de la construcción, Vol. I, Sevilla, 2000, pp. 397-403. También, Gómez de Cózar, J. C. y Benítez Bodes, R. M. "Las soluciones inconclusas de las cubiertas de los templos medievales del Reino de Sevilla, España". Informes de la Construcción, Vol. 60 nº 509 (2008), pp. 57-67. doi: 10.3989/ic.2008.v60.i509.591.

(4) Cómez Ramos, R. Las empresas artísticas de Alfonso X el Sabio. pp. 98-99, Excma. Diputación Provincial de Sevilla, Sevilla, 1979.

(5) Cómez Ramos, R. Los constructores de la España medieval. pp. 73 y 129. Universidad de Sevilla, Sevilla, 2001.

(6) Ladero Quesada, M. A. "Los mudéjares de Castilla en la Baja Edad Media". Historia, Instituciones y Documentos, no 5 (1978), pp. 257-304.

(7) Muñoz Vázquez, M. Documentos inéditos para la Historia del Alcázar de Córdoba de los Reyes Cristianos. Boletín de la Real Academia de Córdoba, nº 72 (1955), pp. 69-88.

(8) Ladero Quesada, M. A. Ob. cit., p. 296.

(9) Vorsevi, S. A. Estudio de la iglesia de S. Pedro de Córdoba (inédito), pp. 14 y 42, Sevilla, 1991.

(10) Ramírez Laguna, A. Obras de emergencia en la iglesia de S. Pedro de Córdoba (informe técnico inédito), Córdoba, 1993.

(11) Vorsevi S. A. Ob. cit., pp., 15-16.

(12) Ramírez Laguna, A. Ob. cit.

(13) Cabrera Ponce de León, A.; Rodríguez López, O. "Rehabilitación de la iglesia de Santiago de Córdoba". Cuadernos de intervención en el Patrimonio Histórico, n 1, Consejería de Cultura y Medio Ambiente, Junta de Andalucía, Córdoba, 1990.

(14) Lara de la Peña, C.; Sanz Cabrera, J. Proyecto de restauración de la iglesia de La Magdalena (inédito), p. 11, Consejería de Cultura y Medio Ambiente, Junta de Andalucía, Córdoba, 1991.

(15) Graciani García, A. (ed.). La técnica de la arquitectura medieval, p. 230, Universidad de Sevilla, Secretariado de publicaciones, Sevilla, 2000.

(16) Karge, H. La catedral de Burgos y la arquitectura del siglo XIII en Francia y España, p. 84, Consejería de Cultura y Turismo, Junta de Castilla y León, Valladolid, 1995.

(17) Jiménez Martín, A. "La primera cantera andalusí". Actas del Tercer Congreso Nacional de Historia de la construcción, Vol. II, Sevilla, 2000, pp. 549-555.

(18) Jiménez Martín, A. Ob. cit., p. 551.

(19) Nieto Cumplido, M. y Luca de Tena y Alvear, C., La Mezquita de Córdoba: planos y dibujos, Colegio Oficial de Arquitectos de Andalucía Occidental, Córdoba, 1992. Velázquez Bosco, R. Medina Azahra y Alamiriya, Junta para ampliación de estudios e investigaciones científicas, Madrid, 1912.

(20) Hernández Jiménez, F. El alminar de Abd Al-Rahman III en la Mezquita Mayor de Córdoba. Génesis y repercusiones, p. 146, Patronato de la Alhambra, Granada, 1975.

(21) Montejo Córdoba, A. J. "El pabellón de abluciones oriental de la mezquita aljama de Córdoba correspondiente a la ampliación de Almanzor". Cuadernos de Madinat al-Zahra, no 4 (1999), pp. 209-231. También, López Cuervo, S. Medina Al-Zahra. Ingeniería y formas, p. 53, MOPU, Madrid, 1983. También, Velázquez Bosco, R. Ob. cit., p. 26.

(22) Vázquez Lesmes, J. R. 1978. "Monasterio y Colegiata de San Hipólito de Córdoba (1343-1399)". Actas del I Congreso de Historia de Andalucía, Vol. 1. Córdoba, 1978, pp. 147-61.

(23) Luna Osuna, D.; Zamorano Arenas, A. M.: "La mezquita de la antigua finca El Fontanar (Córdoba)". Cuadernos de Madinat al-Zahra, no 4 (1999), pp. 145-173.

(24) Hernández Jiménez, F. Ob. cit., pp. 136 y 142.

(25) Tabales Rodríguez, M. A. "Algunas reflexiones sobre fábricas y cimentaciones sevillanas en el período islámico". Actas del Tercer Congreso Nacional de Historia de la construcción, Vol. II, Sevilla, 2000, pp. 1078-1088. 
(26) Graciani García, A. Ob. cit., 247.

(27) Marfil Ruiz, P. Informe y memoria científica. Intervención arqueológica de urgencia en la Iglesia de Santa María Magdalena (inédito). Córdoba, 1996.

(28) Vorsevi S. A. Ob. cit., pp., 5 y 40.

(29) Vorsevi, S. A. Reconocimiento geotécnico. Iglesia de S. Nicolás de Córdoba (inédito), Sevilla, 1995. También, Romero Pérez, F. Proyecto Básico y de Ejecución de recalce de cimentación en muro lateral derecho de la parroquia de S. Nicolás de la Villa (inédito), Córdoba, 1999.

(30) Pinto Puerto, F. "Fábrica y forma del templo gótico". La Catedral gótica de Sevilla. Fundación y fábrica de la obra nueva, pp. 209-96. Secretariado de publicaciones de la Universidad de Sevilla, Sevilla, 2007.

(31) Luna Osuna, D.; Zamorano Arenas, A. M. Ob. cit. También, Tabales Rodríguez, M. A. Ob. cit., p. 1080.

(32) Cortón de las Heras, M. T. La construcción de la Catedral de Segovia (1525-1607), p. 251, Caja de Ahorros y Monte de Piedad de Segovia. Segovia, 1997.

(33) Heyman, J. Teoría, historia y restauración de Estructuras de fábrica, pp. 2-3, Instituto Juan de Herrera, Madrid, 1995.

(34) Bechmann, R. Villard de Honnecourt. La pensée technique au XIII siècle et sa communication, pp. 53-70, Picard, Paris, 1993.

(35) García Ortega, A. J. "Mecanismos de proyecto medievales. El caso cordobés a partir de sus parroquias". Ra, no 5 (2003), pp. 3-12.

(36) Hernández Jiménez, F. "El codo en la Historia Arabe de la Mezquita Mayor de Córdoba. Contribución al estudio del monumento". Al-Mulk. Anuario de Estudios Arabistas, no 2 (1962), pp. 5-52.

(37) Cassanelli, R. Talleres de Arquitectura en la Edad Media, p. 16, Moleiro, Barcelona, 1995. 